\title{
EDITORIAL
}

\section{A consolidação das práticas integrativas e complementares no século 21}

\section{Danilo Ribeiro de Oliveira}

O que já foi denominado práticas alternativas em saúde, ou medicina alternativa, sendo rotulado como superstição, misticismo, ausência de estudos de segurança e eficácia, efeito placebo, dentre outros, passou a ser reconhecido como Práticas Integrativas e Complementares (PICs). As PICs estão embasadas em diferentes racionalidades médicas e de cuidado à saúde, práticas e produtos que não são considerados parte da medicina convencional ${ }^{1}$. Essas racionalidades e práticas partilham uma perspectiva vitalista, centrada na experiência de vida do paciente, com ênfase no indivíduo como um todo, não na doença, apresentando um caráter integrador.

Uma importante contribuição mundial para a valorização das PICs foi a publicação da Organização Mundial da Saúde da "Estrategia de la OMS Sobre Medicina Tradicional 2002$2005 "$. No Brasil, as PICs vêm ganhando destaque a partir de 2006 com a publicação da Política Nacional de Práticas Integrativas e Complementares (PNPIC), visando, dentre os seus objetivos, incorporar e implementar as PICs, principalmente no SUS, na perspectiva da prevenção de agravos e da promoção e recuperação da saúde, com ênfase na atenção básica, voltada ao cuidado continuado, humanizado e integral em saúde ${ }^{3}$.

Recentemente ${ }^{4}$, as PICs reconhecidas pelo Ministério da Saúde, que podem ser ofertadas pelo SUS, foram ampliadas de 19 para 29, compreendendo, dentre elas, apiterapia, aromaterapia, bioenergética, constelação familiar, cromoterapia, geoterapia, hipnoterapia, imposição de mãos, ozonioterapia, terapia de florais, ayurveda, homeopatia, medicina tradicional chinesa, medicina antroposófica, plantas medicinais/fitoterapia, arteterapia, biodança, dança circular, meditação, musicoterapia, naturopatia, osteopatia, quiropraxia, reflexoterapia, reiki, shantala, terapia comunitária integrativa, termalismo social/crenoterapia e yoga.

Portanto, o presente número especial não poderia ter vindo em um melhor momento, quando as PICs avançam em reconhecimento popular e no SUS, possibilitando demonstrar parte da luta de profissionais que militam e atuam, dando suas contribuições, por meio de trabalhos acadêmicos de pesquisa, artigos de revisão, relatos de casos, relatos de experiência etc.

Os artigos científicos, inicialmente, foram organizados em trabalhos que destacam a percepção e a aceitação de profissionais de saúde (Santos et al.; Siqueira et al.) ou de estudantes sobre as PICs (Iozzi et al.; Couto et al.), tais como homeopatia e fitoterapia, dentre outras. A maioria dos trabalhos ressalta a importância de se trabalhar a capacitação/formação em PICs desde a graduação, englobando, ainda, os profissionais já inseridos no mercado de trabalho, especialmente no SUS. Nesse sentido, sequencialmente, Zanella et al. apresentam, em seu trabalho, uma "Proposta de intervenção ensino-serviço de Práticas Integrativas e

\footnotetext{
${ }^{1}$ Tesser, C.D. Práticas complementares, racionalidades médicas e promoção da saúde: contribuições poucos exploradas. Disponível em: https://www.scielosp.org/article/csp/2009.v25n8/1732-1742/pt/

Estrategia de la OMS Sobre Medicina Tradicional 2002-2005. Disponível em: http://apps.who.int/iris/bitstream/handle/10665/67314/WHO_EDM_TRM_2002.1_spa.pdf;jsessionid=12BBF90DCE 7421A88C824C1EF8DCB8A3?sequence=1

Política Nacional de Práticas Integrativas e Complementares em Saúde. Disponível em: http://dab.saude.gov.br/portaldab/pnpic.php

${ }^{4}$ Ministério da Saúde inclui 10 novas práticas integrativas no SUS. Publicado em: 12 de Março de 2018. Disponível em: http://portalms.saude.gov.br/noticias/agencia-saude/42737-ministerio-da-saude-inclui-10-novaspraticas-integrativas-no-sus
} 
Complementares". Sanches et al., por sua vez, demonstram a diversidade das PICs em unidades públicas de saúde da capital fluminense. O trabalho de Borella \& Teixeira já demonstra a preocupação com o controle de qualidade dos insumos farmacêuticos ativos e dos fitoterápicos que podem chegar aos usuários do SUS, por meio de um Programa Municipal de Fitoterapia e Homeopatia. A sessão de artigos científicos é concluída com o trabalho de FalkowskiTemporini et al., o qual demonstra que a "Associação de medicamentos homeopáticos promove diminuição da parasitemia e melhora clínica em camundongos infectados por Trypanosoma cruzi", sendo de grande relevância para a apresentação de resultados do emprego de medicamentos homeopáticos em estudos pré-clínicos.

Para os artigos de revisão, as revisões sistemáticas apresentadas por Silva \& Feitosa evidenciaram a necessidade de estudos observacionais sobre o conhecimento acerca da Política Nacional de Plantas Medicinais e Fitoterápicos (PNPMF) e da Política Nacional de Práticas Integrativas e Complementares (PNPIC) por gestores e profissionais da saúde. É interessante destacar a importância deste número especial em PICs, que trouxe diversos trabalhos acerca do conhecimento da PNPMF e das PNPICs, contribuindo para mudar esse quadro com estudos realizados em diferentes regiões do Brasil. Por fim, o número especial foi contemplado com uma bela revisão elaborada por Abreu e intitulada "O vitalismo das Práticas Integrativas e Complementares e o conceito de campo da ciência moderna", que explica, de forma clara, a concepção holística e vitalista das PICs, compreendendo o ser humano como uma unidade físico-energética/psicofísica, mental e espiritual.

Em relato de caso, foi apresentado o trabalho de Sant'Anna et al. sobre o "Tratamento da Tenossinovite de De Quervain por Acupuntura", corroborando a importância da acupuntura no tratamento de inflamações e desordens musculoesqueléticas.

Os relatos de experiência trouxeram-nos o item mais diverso do número especial. Inicialmente, Vieira et al. e Oliveira-Silva et al. apresentaram as experiências vividas no ensino e na formação voltados às PICs e ao cultivo de plantas medicinais, respectivamente. Em seguida, o trabalho de Sá et al. demonstra como as mídias sociais podem interagir e servir como ferramenta de interlocução com a sociedade no caso das Plantas Medicinais, especialmente no escopo de Programas como Farmácias Vivas.

Ainda dentro de relatos de experiência, a Associação Brasileira de Fitoterapia, no trabalho apresentado por Fiut et al., trás-nos o exemplo e a experiência deles na aplicação interprofissional da fitoterapia. Em sequência, destaca-se o desenvolvimento de um Arranjo Produtivo Local em Plantas Medicinais e Fitoterápicos, no trabalho apresentado por Oliveira \& Martins, bem como o trabalho de estruturação de um programa Farmácias Vivas em uma Instituição Federal de Ensino do Brasil, por Martins et al.

Por último, é apresentado por Baratto a Resenha do livro "Fitoterapia Contemporânea: Tradição e Ciência na Clínica Prática", que tem servido como material didático de grande relevância para a prática da Fitoterapia, trazendo conceitos, técnicas de anamnese, monografias e exemplos de casos clínicos. 